\title{
Cyberbullying across youths in Jordan Community: Perspectives of the Faculty of Education students in Al-Hussein bin Talal University
}

\author{
Dr. Abdullah Al-Darawsheh \\ aldrawsheh@yahoo.com \\ Associate professor \\ Al-Hussein Bin Talal University
}

\author{
Dr. Noor Abutayeh \\ nabutayeh@zu.edu.jo \\ Assistant professor \\ Zarqa University
}

\author{
Dr.Amjad Farhan Alrekebat \\ Amjadamjad74@yahoo.com \\ Al-Hussein Bin Talal University
}

\begin{abstract}
This study aimed at identifying cyberbullying among youths in Jordan community from students' perspectives at the Faculty of Education in Al-Hussein bin Talal University. In order to achieve the study objectives, the quantitative approach was deployed. A questionnaire was developed for data collection. The study sample was randomly selected. There were (185) respondents.

The results revealed that the most common types of cyberbullying among youths in the Jordanian community were respectively as follows: ridicule and discredit $(\mathrm{M}=4.02, \mathrm{SD}=0.89)$, slander, cursing and contempt $(\mathrm{M}=4.01$, $\mathrm{SD}=1.01)$, publishing misleading messages, images and news about others $(\mathrm{M}=4.00, \mathrm{SD}=0.85)$, and publishing jokes that violate general manners $(M=3.60, S D=0.99)$. The average for the responses of the study sample individuals towards the level of cyberbullying among youth from the perspective of the study sample individuals was high with a mean of (3.81) and the standard deviation value was (0.97).

In addition, the results revealed that the most common effects of cyberbullying among youths in the Jordanian community were respectively: The increased levels of violence and individual and group quarrels $(\mathrm{M}=4.00, \mathrm{SD}=$ $0.88)$, the low level of manners and the system of social values $(\mathrm{M}=3.99, \mathrm{SD}=1.33)$, then the loss of cultural identity and substituting it with the global culture $(\mathrm{M}=3.97, \mathrm{SD}=0.91)$, and finally low skills of personal interaction $(\mathrm{M}=3.60, \mathrm{SD}=0.99)$.

In the light of the results, the study recommended the necessity of activating the role of media and educational institutions in educating youths about the risks of practicing cyberbullying as well as activating sanctions and taking the necessary legal measures against those practicing cyber bullying.
\end{abstract}

Keywords: Cyberbullying, social platforms, youths, penal law, Jordan community.

DOI: $10.7176 / \mathrm{JEP} / 12-15-09$

Publication date:May 31st 2021

\section{Introduction}

The phenomenon of cyberbullying spreads in all the world countries, either as developed or developing. Therefore, it became a global phenomenon that should be addressed in all the local and international communities as well as the social and educational institutions. This phenomenon was advocated by the technological advancement and cognitive increase since the end of the twentieth century beginning of this century with regard to the technology of communication networking and the internet and resulted in more facilitation and services in the domain of social communications; it caused radical changes in the human life (AlMakanin, et al, 2018).

Cyberbullying is a deliberate aggressive behavior to which individuals are exposed. It is one of the dangerous behaviors that spread in the developed and developing human communities. Cyberbullying is manifested in several images, including the bully's ability to hide himself, low emotional empathy, the absence of legal accountability, threat, ridicule, slander, cursing and contempt; it results in painful social and psychological effects (Al-Sobaihein, et al, 7, 2013). In addition, it is considered a dangerous problem with negative consequences on youths who are considered as the most common users for the social media sites due to their interesting nature and ease of use, given their nature as a source of information, news and entertainment, where 
they provide users additional advantages that don't exist in conventional means of media and other expression platforms (Hussein, 2016). The main aim of cyberbullying is to harm others. It includes various types of aggression through using modern communication and information technology, emails, chat rooms and the images sent via mobile phones (Kowalski, et.al, 2007, p2). It has adverse effects represented by social isolation, frustration, depression, exclusion, anxiety and stressors. Therefore, the current study aimed at identifying the level and effects of cyberbullying across youths in the Jordanian community.

\section{Problem statement and questions}

The current study ties to identify the level and effects of cyberbullying across youths in the Jordanian community. It is an obvious phenomenon that threatens the security and stability of the community. This phenomenon has been linked to several dangerous effects on youths with taking into consideration the rapid of publishing of any aggressive content. The bully's ability to hide itself under a pseudonym, and the absence of legal accountability enhance, in turn, the increasing the levels of cyberbullying.

With the increasing escalation of the phenomenon of cyberbullying in all its forms via the social media sites, particularly the cyberbullying practiced by youths who express their outrage by ridicule, slander, and contempt against others, Jordan experienced various cases of cyberbullying. For example, the number of cyber crimes in Jordan reached (1821) in 2015, while the number increased to (6200) cyber crimes in (2019).

Therefore, the current study aimed at identifying the level and effects of cyberbullying among youths in the Jordanian community from the perspective of the students of the faculty of education in Al-Hussein bin Talal University.

\section{The study questions}

First question: What is the level of cyberbullying among youths in Jordan community?

Second question: What are the effects of cyberbullying among youths in the Jordanian community?

Third question: What are the suggestions and recommendations that could be provided to stakeholders regarding cyberbullying issue?

\section{The study objectives:}

1- Identifying the level of cyberbullying among youths in Jordan community.

2- Identifying the effects of cyberbullying among youths in Jordan community.

3- Identifying the suggestions and recommendations that could be provided to stakeholders regarding cyberbullying issue.

\section{The significance of the study}

\section{First, the theoretical importance:}

The importance of the current study lays in its topic. After going through the literature review, we found few studies that addressed cyberbullying among youths in Jordan community. This study fills the gap with information needed in this topic. We noticed the demand of more specialized studies that investigate this topic. Therefore, this study is an additional support for Arab and Jordanian literature and libraries.

\section{Second, the scientific importance:}

This study potentially enhances researchers to conduct further studies on this issue. It provides decision-makers, specialists with more information about the violation of values and principles that occurs from some persons using social media platforms, and urges them to set plans and programs to educate community individuals especially students with the potential risks of cyberbullying, and to, some extent, reduce the spread of this phenomenon across people. The study provides recommendations and suggestions to both stakeholders and individuals of how to reduce this phenomenon.

\section{Theoretical and procedural definitions:}

Bullying, linguistically is used to refer to the man with bad manners; he changed the expressions of his face, which means that he grimaced and frowned his eyebrows (Ibn Manthour, 1977: 285). 
Bullying, conceptually refers to a psychological state that motivates the individual either deliberately or undeliberately to harm another person physically or psychologically in order to intimidate and have control over him; knowing that the targeted person has no ability to defend himself (Al-Hamadani, 2011: 16).

Cyberbullying : it is the aggressive or harmful behaviors that take place via the electronic means, such as the Internet and mobile phones and are directed towards other groups or individuals (Peluchette,et,al,2015).

Cyberbullying is also defined as any behavior that is practiced by an individual or a group of people with regard to using the new information technology and means of communication and their various applications. Such a behavior aims to cause a frequent deliberate harm to an individual or a group of people (Al-Shennawi, 2014: 4). Cyberbullying is procedurally defined as a frequent deliberate behavior which aims to harm others and hurting them socially and psychologically, where it is implemented via social media sites.

\section{The theoretical framework:}

Communication and information technology revolution change the world to a small village, where individuals spend a lot of time using those techniques due to the ease of using them; an individual can easily communicate with another individual in any part of the world in case the other individual has a similar application (Fifi, 2015).The most common social media applications are (Facebook, Twitter, Instagram, WhatsApp, YouTube), where social communication among members of a certain site is performed by means of comments, likes, sharing, mention, poke, games, group conversation (Reinhalter, et,al, 2014).

Several motives push an individual to transfer from the real world to the virtual world, including free time, unemployment, marketing as well as making friendships with friends who share similar interests and content in settings that cancel all the spatial and geographical barriers and go beyond the international borders (Salman, 2017). Lee, et. al. (2017) suggested that the expanding size of electronic friendships has a strong impact on cyberbullying. In addition, Bottino, et, al. (2017) revealed that cyberbullying increases with the increased time dedicated to using the internet with at least three hours per day and the number of sent messages with an average of (50) messages per day.

\section{The forms of cyber bullying:}

Cyberbullying is considered as a deliberate violent aggression towards others. It is represented by committing the negative behaviors, such as ridicule, slander, ignorance, marginalizing, cursing, contempt and mockery (Qotami, et al, 2009).

The most common forms of cyberbullying include:

1- Direct bullying: By using the internet for threat and insulation, sending obscene videos, images or drawings that violate the general accepted manners or sending harmful viruses deliberately to others.

2- Indirect bullying: This type of bullying takes place without being noticed by the victim, such as betraying someone or pretending to be someone else, where bullies publish abusive content via mobile phones, e-mail or social media sites.

(Miqrani, 2018: 2) suggested that there are several forms of cyberbullying, including the written bullying, which uses the behavior of written or verbal bullying, such as phone calls, text messages and e-mails as well as visual bullying, such as publishing obscene images. Other forms include exclusion, where an individual is excluded from chatting or Internet groups. Identity theft is the most developed types of cyberbullying; it is represented by robbing the identity of another person and entering to his personal information or using the account of another person.

\section{The characteristics of cyberbullying:}

The phenomenon of cyberbullying is characterized by causing harm to others in a frequent, deliberate and cheating way, where the bully may use a pseudonym to protect itself. Cyberbullying has negative consequences that are represented by the easy escape of the bully without being exposed to any sanctions or accountability. The bully is not sympathetic with the victim due to the absence of human feelings (Al-Shennawi, 2014).

The bully can easily reach the victim via the mobile phone, the email or social media sites anytime and anywhere throughout the world (Miqrani, 2018).

Cyberbullying is characterized by low level levels of accountability on the side of the bully, where the victim is exposed to such a bullying at any time, with the possibility of violating the privacy of homes, mobile phones and 
computers (Juvonen, Wang and Espinoza, 2009).

Al-Sarayreh, 2007 suggested that people tend to use cyberbullying since they can use a pseudonym without the need to uncover their real identity, so they can easily cheat others in a virtual world that is free from surveillance. Al-Zahrani, 2015 investigated the ratios of cyberbullying among the students of postgraduate studies and suggested that $(27 \%)$ of them practiced cyberbullying at least once or twice, while $(57 \%)$ of the students noticed that another student is exposed to bullying and that students are exposed to cyberbullying by strangers whom they knew via the internet, and that the phenomenon is more common among males as compared to females.

\section{The factors of cyber bullying}

Cyberbullying leads to depression and stress among victims. Those victims could also suffer from fear feelings, anxiety, lack of safety, isolation, distraction as well as somatic and psychological disorders that may lead to committing suicide. (Waasdorp, et al, 2015) suggested that cyberbullying was largely linked to depression, where victims have no confidence in the possibility of doing anything to solve the problem of cyber bullying. As for analyzing the data of behavioral surveys for the risks facing youths, Nikolaou,2017 suggested that the victims of cyberbullying have suicide ideation with a percentage of $(15 \%)$ and suicide attempt with a percentage of $(9 \%)$.

The author suggested that the causes of cyberbullying among youths are related to unemployment, failure in general or professional life, feeling of fears, frustration, outrage, depression, avoiding participation in social activities and social isolation from the community.

(Cassidy, et, al, 2017) suggested that there are some noticed psychological symptoms due to cyberbullying among the students of high schools, such as high levels of depression, anxiety and somatic pains and low selfesteem related to the cases of cyberbullying.

Gkiomisi et. al. (2017) suggested that in (40\%) of bullies were strangers, (60\%) of victims didn't ask for help and $(20 \%)$ suffered from psychological symptoms.

The situation of the Jordanian legislator from cyberbullying, and the sanctions for that as mentioned in the Jordanian Penal code:

"In the Jordanian legislation, there is no such a crime referred to as cyber bullying; however, the legislator considered the acts performed by the bully as behaviors that are punished and criminalized under law. Therefore, they are considered within the crimes of threat, exploitation, slander, discredit, contempt and violation of privacy of others, where the sanctions of these behaviors may reach the imprisonment for three years and no less than three months."

(Jordanian penal code, 2015).

\section{The theories interpreting the study topic}

Psychoanalytic theory

Freud suggested that the human's personality consists of three parts; the ID, the ego and the super ego. The ID is responsible for uncoordinated instinctual desires and seeks to satisfy desires and gain pleasure, some scientists referred to it as the primitive part of personality. The ego develops later on and mediates between the unrealistic id and the real world; it suppresses the ID. The ego is responsible for delaying desires among young children, so that they don't commit the deviant behavior. The superego develops from the ego; it refers to a number of standards and values upon which the young children grow, and it is responsible for such issues as regret, shame, and feeling guilty.

The advocates of this theory suggested that crime and deviant behavior could be interpreted based on three resources. Among healthy children the three parts work together in a coordinating manner. However, when there is a conflict between the components of personality, crime or the deviant behavior may take place. The first source of crime could be attributed to the weak superego, which can't control the desires of the id, and the individuals who lack the developed superego are referred to as psychopaths or sociopaths; those individuals could commit sexual, murder and violence crimes, where those individuals are characterized by focusing on their individual interests. The second resource of crime is represented by the concept developed by Freud, which is "sublimation", where the concept interprets the set of processes performed by the individual to substitute something for another thing symbolically. It is well-known that mothers have more role to do with the process of upbringing children (as noticed by Freud himself); here children substitute their bad and negative attitudes towards their mothers by an acceptable thing in the community. The last resource to interpret crime and deviant 
behavior is related to the desire or passion to death, represented by several images, such as smoking, driving quickly, bad nutrition... etc., where those dangerous human activities are interpreted based on (thanatology). The desire to devastate oneself may push individuals to commit dangerous crimes, including harm, robbery, murder, prostitution and substance abuse (Al-Wereikat, 2013).

\section{Akers Social Learning Theory}

Akers suggested that the origin of enhancing deviances has more to do with common rationalities as well as the different groups and subcultures in the community. The main point of social learning theory could be summarized as follows:

1- The human behavior is designed to seek for enjoyment and avoid pain.

2- The two combined concepts of behavior are reward and punishment, where reward increases the frequency of the behavior while punishment decreases the frequency.

3- The criminal behavior is an acquired behavior, which is learned by the social and financial enhancements, just like other behaviors are acquired. These are the products of previous and current experiences; therefore, all individuals have different sets of learned behaviors and their consequences.

4- Social enhancements work as reasons for learning behaviors as good or bad ones, desired or undesired ones, and the social environment provides various behaviors that can be imitated.

5- Social customs which are learned by the same way other behaviors are learned; they work as signs concerning the nature of a certain behavior as enhanced or enhancing.

6- Customs help to learn crime as direct signs for the advent of reward or as justifications used to avoid punishment for a certain criminal behavior.

7- Criminal behavior is a behavior that has been enhanced by customs and financial rewards in the subcultural environment of the individual.

Financial rewards are usually provided by the crime itself. Therefore, when individuals are deprived, they could maintain the criminal behavior via its own rewards (Al-Badaineh, et al, 2013).

Symbolic interactive theory: It is one of the theories that linked between the human behavior and attitudes or the symbols relating to it. The most prominent scientists who advocated this theory are "Herbert Blumer, 19001987" and "Maximilian Carl Emil Weber 1864-1920", and was developed by the American scientist " Herbert Mead, 1863-1931". The theory emphasized that the human behavior depends on the individual's understanding for the social phenomena surrounding him by understanding the attitudes of the individuals with whom he communicates. This type of interaction takes place by understanding the symbols upon which individuals agree; such interaction includes the common laws, signs, and relationships as well as the auditory and visible language and other events that constitute the social action.

The symbolic interaction between individuals refers to the social learning and teaching process that takes place between people through symbols; most interaction occurs based on face to face communication. However, it may take place in other forms, such as the symbolic communication between the individual and the programs or the movies that he watches via TV screens, means of media or the news that he hears via the various news channels. Symbolic interaction is one of the human life characteristics, where individuals can communicate using the symbols which developed over hundreds of years (Al-Wereikat, 2013). The symbolic interactive theory is based on basic pillars that demonstrate the mechanism of symbols with regard to shaping the human behavior as follows, (Hebermas, 1987):

1- Interaction between individuals in the form of continuous sequence between each individual and the other, between the individual and the group and between a certain group and other groups.

2- Those interactions are characterized by flexibility, which means that humans can behave during a number of circumstances in one way at the same time, or in different ways at another time based on the symbols which represent a set of signs that people use to facilitate the communication process; they include meanings, impressions, and mental images.

3- The individual's ability to undergo the role specified to him due to the interaction: others' expectations about the individual's behavior in certain circumstances represent texts that should be recognized in order to be performed by the individual, and the individual will also have a conceptualization about himself that relates to his experiences and ability to interact with others.

4- Human behaviors are a product of the interaction between the active self of the human psyche that is consisted of internal inherent factors and external societal factors, with the surrounding social environment, where the socialization process affects this interaction by shaping the human psyche in accordance with the social standards, so that the individual is able to live within the community and identify with the socially- 
accepted behavior; the individual will be more inclined towards accepting the controls and standards of the social organization to which he belongs, such as values, customs, and social traditions.

5- Social disintegration begins to emerge among people when they don't comply with the social standards and controls of the community with which they interact; therefore, the deviant behavior and crime begin to emerge in the community (Al-Wereikat, 2013).

\section{Literature review}

Khalil, et al. (2019) conducted a study entitled "investigating some demographic variables related to being a victim of cyberbullying among the University students". The study sample consisted of (261) male and female students. The results revealed that there are no statistically significant differences between the mean scores for both males and females in the total score for the scale of cyberbullying and its dimensions (abuse, electronic harassment, hiding identity, violation of privacy, ridicule and discredit). The results also revealed that there are no statistically significant differences between the mean scores for the sub-dimensions for the scale of the victims of cyberbullying (abuse, electronic harassment, covering identity, violation of privacy, ridicule and discredit).

Another study discussed the same issue, Al-Sayid, (2019), he conducted a study entitled "bullying via social media sites and its relationship with achievement motivation among adolescents in the governorate of Cairo in Egypt". The study sample consisted of (250) male and female students. The results revealed that the study sample individuals have high levels of Conceptualization regarding the prevalence of bullying as a violent behavior among the users of social media sites from the study sample individuals. The results revealed that the prevalence of cyberbullying contributed to increasing the cases of violence and quarrels among students. It also increased the feelings of isolation and reduced achievement motivation among them.

Abdullah (2019) suggested that there are differences between those exposed or not exposed to cyberbullying regarding the big five factors of personality among a sample of adolescents. The study sample consisted of (224) respondents. The results revealed that the dimension of privacy violation was the most common feature of being exposed to cyber bullying, followed by sexual harassment, then exclusion, threat and humiliation and finally ridicule and discredit. In addition, Al-Rahamneh (2018) conducted a study entitled " discourse of hatred in Facebook in Jordan, a survey study". The study sample consisted of (400) respondents from Amman. The results showed that the concept of hatred discourse was manifested in the form of distorting facts. The results revealed that some social media sites include a symbolic invitation to violence by evoking conflicts between people as well as spreading isolation and dispute to weaken social relationships between the members of community, in addition to evoking intellectual and religious racism. The results revealed that the extent to which hatred discourse affects societal violence, either as verbal or symbolic, depends on the individual's culture, social prestige and academic level.

In Saudi Arabia comes Al-Anezi's study (2017), which was entitled "cyberbullying across social media sites and its relationship with the patterns of school violence in Riyadh in the kingdom of Saudi Arabia". The study consisted of (505) students, and (37) counselors. The results revealed that the most common type of bullying was publishing video clips that evoke ridicule as well as publishing individuals' images without taking their consent. The results revealed that the most common type of violence among students was sarcasm and slandering. The results also revealed that the most important methods for preventing cyberbullying was related to setting the deterrent sanctions and laws for cyberbullying as well as educating students about the risks of cyberbullying and the way of preventing it across social media sites.

In Jordan, Al-Fawa'er (2016) study that is entitled " the impact of social media sites on the intellectual security of the University youth in Jordan from the perspectives of female students in Irbid University College, Balqa' University". The study sample consisted of (225) students in the bachelor degree stage enrolled for the second semester of the academic year. The results revealed that social media sites have an important role in threatening the intellectual security and the ethical and social domains among the University students, in addition to their impact on attitudes and opinions.

Sa'id (2017) study found that the most prominent patterns of cyberbullying was publishing video clips and images that evoke ridicule from the individuals who appear in those videos or images without taking their consent. The results showed that the most common type of school violence was slander and cursing.

Another study of Al-Shennaw (2014) who conducted a study entitled "The levels of using social media sites (Facebook) and their relationship with psychological adjustment among the adolescent students". The study 
sample consisted of (466) male and female students from the tenth and eleventh grades in the villages of AlBotouf Plain in Al-Jaleel. The results revealed that there is a negative relationship between the period that adolescents spend in using Facebook and their level of psychological adjustment. The results showed that there are no statistically significant differences on the scale of psychological adjustment attributed to the impact of gender. Moreover, Reynolds', et al. study. (2018) aimed at investigating the experiment of using social media sites in higher education and the need to introduce a rational and sustainable development for teaching methods via the internet in England. The study sample consisted of (60) master degree students in the British Universities. The results revealed that there are positive effects for this approach on some participants. However, there are some negative effects that are represented by symbolic violence that is manifested in the form of deliberate gestures and comments to stimulate ridicule in some situations.

Sekol, et al, (2016) conducted a study entitled "personality traits of bullying victims among youths in care houses". The study sample consisted of (601) male and female respondents. The results revealed that the study sample individuals lack self-esteem. The results showed that being exposed to bullying was more related to the neurotic personality among males and females.

Kurcaburum's, et al. study (2016) aimed at exploring the relationship between the problematic use of the internet and the attitudes towards cyber violence among adolescents ". The study sample consisted of (205) high school students. The results revealed that there is a statistically significant positive relationship between misusing the internet and the daily time spent on using the internet as well as the attitudes towards cyber violence and its subdimensions (enjoyment, disguise, acceptance, and anxiety). The results revealed that there are higher levels of anxiety concerning being exposed to cyberbullying among females as compared to males. The results also showed that it is possible to predict the attitudes towards cyber violence through the problematic use of the internet.

John (2013) investigated the relationship of social media sites (Facebook, twitter, LinkedIn, and MySpace) with deviant thinking among the students of the urban University in the South East of the USA. The study sample consisted of (467) respondents. The survey focused on the aim of using social media sites in general. The results revealed that there is a strong relationship between the way of using social media sites and thinking. The results revealed that there is a positive relationship between using social media sites (Facebook, twitter, LinkedIn, MySpace) and the deviant thinking, where the deviant thinking increases with the more use of social media sites.

\section{The study methodology}

The study used the quantitative approach by deploying the social survey, which included conducting office survey and reviewing the theoretical and field studies in order to identify the bases upon which the theoretical framework is base and identifying the most important previous studies that are considered as a vital cognitive support for the current study.

As for the analytical field domain, the comprehensive survey was constructed. The data we gathered were analyzed using SPSS. It is noteworthy that the social survey approach is the most commonly used approach in social sciences, where it contributes to achieving the objectives of the scientific research, in terms of description, interpretation and generalization.

\section{The study population}

The study population consisted of all the students in the faculty of education in Al-Hussein Ibn Talal University, with total of (900) male and female students, according to the statistics of the department of admission and registration during the second semester (2020-2021).

\section{The study sample}

The study sample was chosen randomly and the questionnaire was distributed to the study sample individuals that consisted of (200) respondents. After reviewing the returned questionnaires, (15) questionnaires were excluded since they were not completed as desired. Therefore, the final valid questionnaires for analysis were (185) respondents.

\section{The study instrument}

After reviewing the previous studies, a questionnaire was developed for data collection, in a manner that corresponds with the nature of the study problem and its dimensions. The questionnaire included indicators that measure the level and effects of cyberbullying among youths in the Jordanian community, based on previous studies, such as (Sa'id, 2016), (Khalil, et al, 2019), (Al-Shennawi, et al, 2014) and (Kurcaburum, and Bastug, 
2016).

The questionnaire consisted of two parts:

The first part: It consisted of the personal data about the study sample individuals, including (gender, educational qualification, number of family members, age, and monthly income).

The second part: It included the domains of the study instrument and included (34) items distributed within two dimensions, as follows:

First: this axis aims to measure cyberbullying among youths in the Jordanian community, and consisted of (16) items.

Second: aims to measure the effects of among youths in the Jordanian community, and consisted of (18) items.

The standard of judging means

In order to determine the level of estimates of the study sample individuals regarding the items of the study instrument and each of its dimensions, the researcher used the following statistical standard according to the means: the highest score - the lowest score/ the number of levels, $5-1 / 3=1.33$; therefore, the levels become as follows : (1-2.33) low, (2.34-3.67) medium, and (3.68- 5) high.

\section{The study validity}

The validity of the study scale was verified by two ways:

The validity of arbitrators: in order to verify the clarity of items and their compatibility to the Jordanian environment, the scale was introduced to six arbitrators from the faculty members in Al-Hussein Ibn Talal University, Mu'tah university and the University of Jordan. In the light of the results, the primary version of the scale, some modifications were performed, in relation to the clarity of the items and its compatibility to the study objective. The required modifications were performed based on the feedback, and the scale maintained all the (34) items. An agreement of (89\%) among arbitrators was adopted as a criterion for accepting or rejecting the item.

\section{The study reliability}

Cronbach alpha formula was used to verify the internal consistency of the scale items by inserting the study data to the statistical software for processing. The value of reliability coefficient reached $(0.865)$ which are acceptable to apply this instrument to the study sample individuals.

\section{The method of data analysis}

The study data were analyzed using the statistical package for social sciences SPSS. The descriptive statistical methods of (means, frequencies and percentages) were used to describe the characteristics of the study sample and answer the study questions. One-way Anova, t-test and f-test for independent samples were used to detect whether there are statistically significant differences in the responses of the study sample individuals towards the study axes.

\section{Results and findings \\ The demographic characteristics}

Here is a display for the demographic characteristics of the study sample individuals as shown in table (1) . 
Table (1)

Describing the characteristics of the study sample individuals

\begin{tabular}{|c|c|c|c|}
\hline Variable & Category & Number & Percentage \\
\hline \multirow[t]{3}{*}{ Gender } & Male & 84 & $45.40 \%$ \\
\hline & Female & 101 & $54.59 \%$ \\
\hline & Total & 185 & $100 \%$ \\
\hline \multirow[t]{5}{*}{ Educational qualification } & First & 35 & $18.91 \%$ \\
\hline & second & 60 & $32.43 \%$ \\
\hline & Third & 56 & $30.27 \%$ \\
\hline & Fourth & 34 & $18.37 \%$ \\
\hline & Total & 185 & $100 \%$ \\
\hline \multirow[t]{5}{*}{ Number of family members } & 3 or less & 52 & $28.10 \%$ \\
\hline & $4-6$ & 67 & $36.21 \%$ \\
\hline & $7-9$ & 36 & $19.45 \%$ \\
\hline & More than 10 & 20 & $10.81 \%$ \\
\hline & Total & 185 & $100 \%$ \\
\hline \multirow[t]{5}{*}{ Age } & Less than 20 & 81 & $43.78 \%$ \\
\hline & $21-23$ & 40 & $21.62 \%$ \\
\hline & $24-26$ & 28 & $15.13 \%$ \\
\hline & More than 26 & 36 & $19.45 \%$ \\
\hline & Total & 185 & $100 \%$ \\
\hline \multirow[t]{6}{*}{ Monthly income } & Less than $250 \mathrm{JD}$ & 31 & $16.75 \%$ \\
\hline & $251-300$ & 42 & $22.70 \%$ \\
\hline & $301-400$ & 57 & $30.81 \%$ \\
\hline & $401-500$ & 25 & $13.51 \%$ \\
\hline & More than 500 & 30 & $16.21 \%$ \\
\hline & Total & 185 & $100 \%$ \\
\hline
\end{tabular}

\section{The study questions}

First question: what is the level of cyberbullying among youths in the Jordanian community?

In order to answer this question, the means and standard deviations were calculated for the responses of the study sample individuals towards the level of cyberbullying among youths in the Jordanian community from the perspective of the study sample individuals. Table (2) shows the results ordered in a descending way according to the level.

Table (2)

Means and standard deviations for the responses of the study sample individuals towards the level of cyberbullying among youths in the Jordanian community

\begin{tabular}{|lcccc|}
\hline \multicolumn{1}{c}{ Item } & Mean & SD & Order & Level \\
\hline Ridicule and discredit & 4.02 & 0.89 & 1 & High \\
\hline Slander, cursing and contempt & 4.01 & 1.01 & 2 & High \\
\hline Violating privacy of others & 4.00 & 0.95 & 3 & High \\
\hline $\begin{array}{l}\text { Publishing misleading messages, images and news about } \\
\text { others }\end{array}$ & 3.96 & 0.85 & 4 & High \\
\hline Humiliation and character assassination & 3.86 & 0.90 & 5 & High \\
\hline Ridicule and sarcasm of the published posts & 3.85 & 1.03 & 6 & High \\
\hline $\begin{array}{l}\text { Sexual harassment of the opposite gender by publishing } \\
\text { harmful videos ,images and drawings }\end{array}$ & 3.80 & 1.14 & 7 & High \\
\hline Severe and harsh critique against others & 3.79 & 1.11 & 8 & High \\
\hline Promoting rumors and misleading news to harm others & 3.78 & 1.06 & 9 & High \\
\hline Sending provocative messages and images to others & 3.75 & 0.94 & 10 & High \\
\hline Sending messages and images to threat others & 3.72 & 0.90 & 11 & High \\
\hline $\begin{array}{l}\text { Publishing personal videos and images that violate others' } \\
\text { privacy }\end{array}$ & 3.70 & 0.92 & 12 & High \\
\hline Publishing videos and images that harms others' reputation & 3.67 & 0.94 & 13 & High \\
\hline exclusion & 3.65 & 1.01 & 14 & Medium \\
\hline Publishing jokes that violate general manners & 3.60 & 0.99 & 15 & Medium \\
\hline average & 3.81 & 0.97 & - & High \\
\hline
\end{tabular}


Table (2) shows that the most common types of cyberbullying among youths in the Jordanian community were respectively as follows: ridicule and discredit $(\mathrm{M}=4.02, \mathrm{SD}=0.89)$, slander, cursing and contempt $(\mathrm{M}=4.01, \mathrm{SD}=$ $1.01)$, publishing misleading messages, images and news about others $(\mathrm{M}=4.00, \mathrm{SD}=0.85)$, and publishing jokes that violate general manners $(\mathrm{M}=3.60, \mathrm{SD}=0.99)$. The average for the responses of the study sample individuals towards the level of cyberbullying among youths from the perspective of the study sample individuals was high with a mean of (3.81) and the standard deviation value was (0.97).

The second question: what are the factors of cyberbullying among youths in the Jordanian community? In order to answer this question, the means and standard deviations were calculated for the responses of the study sample individuals towards the level of cyberbullying among youths in the Jordanian community from the perspective of the study sample individuals. Table (3) shows the results ordered in a descending way according to the level.

Table (3)

Means and standard deviations for the responses of the study sample individuals towards the factors of cyberbullying among youths in the Jordanian community

\begin{tabular}{|c|c|c|c|c|}
\hline Item & Mean & SD & Order & Level \\
\hline $\begin{array}{l}\text { The increased levels of violence and individual and group } \\
\text { quarrels }\end{array}$ & 4.00 & 0.88 & 1 & High \\
\hline The low level of manners and the system of social values & 3.99 & 1.03 & 2 & High \\
\hline $\begin{array}{l}\text { The loss of cultural identity and substituting it with the } \\
\text { global culture }\end{array}$ & 3.97 & 0.91 & 3 & High \\
\hline The lack of privacy among the users of social media sites & 3.95 & 0.89 & 4 & High \\
\hline Defamation, scandal and harassment & 3.93 & 0.88 & 5 & High \\
\hline Weak social relationships among the community members & 3.90 & 0.95 & 6 & High \\
\hline $\begin{array}{l}\text { The spread of the ideas and behaviors that contradict with } \\
\text { the values and traditions }\end{array}$ & 3.89 & 0.94 & 7 & High \\
\hline The lack of shame among youths & 3.88 & 1.05 & 8 & High \\
\hline Exposure to cyber crimes & 3.86 & 0.98 & 9 & High \\
\hline The spread of crimes and sexual deviances among youths & 3.85 & 1.12 & 10 & High \\
\hline The law levels of participation and expression of opinion & 3.82 & 0.97 & 11 & High \\
\hline $\begin{array}{l}\text { The spread of extremist and terrorist organizations that } \\
\text { affect the ideation of youths }\end{array}$ & 3.81 & 0.90 & 12 & High \\
\hline The feeling of social isolation among youths & 3.80 & 1.02 & 13 & High \\
\hline Low confidence in dealing with others & 3.79 & 0.91 & 14 & High \\
\hline Family disintegration & 3.78 & 0.87 & 15 & High \\
\hline Lack of humanity and empathy with others & 3.75 & 0.96 & 16 & High \\
\hline Fraud and blackmail & 3.69 & 0.93 & 17 & High \\
\hline Low skills of personal interaction & 3.60 & 0.99 & 18 & Medium \\
\hline average & 3.84 & 0.95 & - & High \\
\hline
\end{tabular}

Table (3) shows that the most common effect of cyberbullying among youths in the Jordanian community from the perspective of the study sample individuals was " the increased levels of violence and individual and group quarrels" ( $\mathrm{M}=4.00, \mathrm{SD}=0.88)$, followed by " the low level of manners and the system of social values" $(\mathrm{M}=3.99, \mathrm{SD}=1.03)$, then " the loss of cultural identity and substituting it with the global culture" $(\mathrm{M}=3.97, \mathrm{SD}=$ $0.91)$ in the third rank, while " low skills of personal interaction" was in the last place $(\mathrm{M}=3.60, \mathrm{SD}=0.99)$.

The average for the responses of the study sample individuals towards the effects of cyberbullying among youths from the perspective of the study sample individuals was high with a mean of (3.84) and a standard deviation of $(0.95)$.

\section{Discussion}

Discussing the results of the first question: what is the level of cyberbullying among youths in the Jordanian community from the perspective of the study sample individuals?

The results revealed that the most common levels of cyberbullying among youths in the Jordanian community from the perspective of the study sample individuals was ridicule and discredit $(\mathrm{M}=4.02, \mathrm{SD}=0.89)$, followed by slander, cursing and contempt $(\mathrm{M}=4.01, \mathrm{SD}=1.01)$, publishing misleading messages, images and news about others $(\mathrm{M}=4.00, \mathrm{SD}=0.85)$, while publishing jokes that violate general manners was in the last place $(\mathrm{M}=3.60$, 
$\mathrm{SD}=0.99)$.

The average for the responses of the study sample individuals towards the level of cyberbullying among youths from the perspective of the study sample individuals was high $(\mathrm{M}=3.81, \mathrm{SD}=0.97)$. The results is compatible with the studies conducted by Khalil, et al, (2019), Al-Sayid (2019), Abdullah (2019), Al-Anezi (2017), Kurcaburum, and Bastug (2016) and John (2013).

Therefore, the researchers suggested that cyberbullying weakens the cultural identity and violates individuals' privacy, since the bully can hide himself under pseudonyms, in addition to the lack of legal accountability.

Discussing the results of the second question: what are the factors of cyberbullying among youths in the Jordanian community from the perspective of the study sample individuals?

The results revealed that the most common effects of cyberbullying among youths in the Jordanian community were respectively: The increased levels of violence and individual and group quarrels $(\mathrm{M}=4.00, \mathrm{SD}=0.88)$, the low level of manners and the system of social values $(\mathrm{M}=3.99, \mathrm{SD}=1.33)$, then the loss of cultural identity and substituting it with the global culture $(\mathrm{M}=3.97, \mathrm{SD}=0.91)$, and finally low skills of personal interaction $(\mathrm{M}=3.60, \mathrm{SD}=0.99)$.

The average for the responses of the study sample individuals towards the effects of cyberbullying among youths from the perspective of the study sample individuals was high with a mean of (3.84) and a standard deviation of (0.95).

The results agreed with the studies that were discussed by Al-Fawa'er (2019), Sa'id (2017), Al-Rahamneh, (2017) and Reynolds et. al (2018).

The researchers suggested that cyberbullying has painful effects on the individual and community, since it contributes to discrediting others and threatening them by using images and videos that violate public manners and values, and this increase the severity of stress and violence between individuals.

\section{Recommendations}

Based on the study results, the study recommended the following:

1- The necessity of activating the role of media and educational institutions in educating youths about the risks of cyberbullying in order to strengthen their feelings about the importance of good treatment and objective cultural dialogue with others, in addition to the ways of avoiding it.

2- Setting the deterrent sanctions and laws against cyberbullying.

3- Activating the role of security authorities and youth organizations with regard to combating the culture of cyberbullying among youths via the counseling and guidance programs which aim to create communication and understanding among them since they are the most-using category of social media sites.

4- Conducting further applied studies to investigate the issue of cyberbullying and identifying the effects of cyberbullying on the individual and community.

\section{References}

Abdullah, Ahmad Amr, (2019), the differences between those exposed and not exposed to cyberbullying in the major personal factors of personality among an adult sample, the Journal of Humanities and Social Sciences, Issue (54), Imam Muhammad bin Saud Islamic University, the Kingdom of Saudi Arabia.

Al-Anezi, Monawir Obaid (2017) Cyberbullying across social media sites and its relationship to the patterns of school violence, unpublished PhD, Naif Arab University for Security Sciences, Riyadh, Saudi Arabia.

Al-Badayneh, Thiab; And Al-Khuraisheh, Rafi' (2013). Criminology Theories: Introduction, Evaluation and Applications, First Edition, Dar Al Fikr Publishers and Distributors, Amman.

Al-Fawa'er, Hiyam Yousef Suleiman (2016) The impact of social media sites on the intellectual security of university youth in Jordan from the perspective of female students of Irbid University College / Balqa' University, the Journal of Education, the Faculty of Education, Al-Azhar University.

Al-Hamdani, Abdul-hassan Abdul-Saheb Hassan, (2012), Bullying behavior among children and adolescents and its relationship to age, gender and birth order, Master Thesis, The Faculty of Education, Ibn Rashid, University of Baghdad.

Al-Makanin, Hisham AbdulFattah, and Yanas, Najati Ahmad, and Al-Hiari, Ghalib (2018), cyberbullying among a sample of behaviorally and emotionally disturbed students in the city of Zarqa, the journal of Psychological and educational studies, the University of Sultan Qaboos, 12 (1): p. 179-197.

Al-Rahmaneh, Nasser (2018) "Hatred Speech in the Facebook Network in Jordan - A Survey Study, 
Unpublished Master Thesis, Middle East University, Amman, Jordan.

Al-Sarayreh, Mona (2007). Differences in self-esteem, family and social relationships, mood, leadership, and academic achievement between bullies, their victims, and ordinary adolescents. Unpublished PhD, the Faculty of Graduate Studies, the University of Jordan.

Al-Sayid, Aya Mohammad (2019) The relationship of bullying through social media with achievement motivation among adolescents, the Journal of Arab Research in the Fields of Specific Education, Arab Educators Association, Vol. 1, Issue 16.

Al-Shennawi, Amina Ibrahim, (2014), Psychometric Efficiency of the Scale of Bullying (Bully - Victim), the Journal of Service Center for Research Consultations, Psychological and Social Studies Section, the Faculty of Arts, Manoufia University, November issue (1-50).

Al-Sobhiyin, Ali Mousa, Al-Qudah, Mohammad Farhan, (2013), Bullying behavior among adolescent children (its concept - its causes - its treatment), Naif Arab University for Security Sciences, Riyadh.

Al-Wereikat, Ayid (2013), theories of criminology, second edition, Dar Al-Shorouq for publishing and distribution, Amman, Jordan.

Al-Zahrani, A. M. (2015). Cyberbullying among Saudi's higher-education students: implications from educators and policymakers. World Journal of Education, 5(3), 15-32

Bottino, S. M. B., Bottino, C., Regina, C. G., Correia, A. V. L., \& Ribeiro, W. S. (2015). Cyberbullying and adolescent mental health: systematic review. Cadernos de saudepublica, 31, 463-475.

Cassidy, W., Faucher, C., \& Jackson, M. (2017). Adversity in university: Cyberbullying and its impacts on students, faculty and administrators. International journal of environmental research and public health, $14(8), 888$.

Dilmaç, B., \& Aydoğan, D. (2010). Values as a predictor of cyber-bullying among secondary school students. International Journal of Social Sciences,5(3), 185-188.

Fifi, Ahmad Tawfiq (2015), Awareness about the educational uses of social media sites among the high school teachers in Sohaj, the journal of the faculty of education, Asyout, Egypt.

Gkiomisi, A., Gkrizioti, M., Gkiomisi, A., Anastasilakis, D. A., \& Kardaras, P. (2017). Cyberbullying among Greek high school adolescents. The Indian Journal of Pediatrics, 84(5), 364-368

Hussein, Ramadan Ashour, (2016), The Factorial Structure of the Electronic Bullying Scale as Perceived by the Victim among an Adolescent Sample, The Arab Journal of Studies and Research in Educational and Human Sciences, (4): (40-50).

Ibn Manthour, Abi Al-Fadl Jamal Al-Din, Arab Tongue, edition (1), part (6), Dar Sad for Publishing, Beirut.

John, Gironda. (2013). Social Networking Sites And Planned Behavior. Academic Search Complete, Summer Educators' Conference Proceedings. Vol. 23, p387-388.

Juvonen, J., \& Gross, E. F. (2008). Extending the school grounds? Bulling experiences in cyberspace. Journal of School Health, 78 (9), 469-505.

Khalil, Asma' Al-Sayid Mohammad, Al-Bilawi, Eihab Abdul-Aziz Abdul-Baqi, Saqr, Hala Ahmed AbdulHamid, (2019), a study of some demographic variables associated with being a victim to cyberbullying among university students, the Journal of Studies and Research in Specific Education, Zaqaziq University, the second Issue, ( 85-99).

Kowalski, R,M, \& Limber,s.P.(2007).Electronic bulling among middle school students, Journal of adolescent health ,(41),(6),S22-S30

Kurcaburum, K. \&Bastug., I (2016). Predicting cyberbullying tendencies if adolescents with problematic internet use. International Journal of Social Science, 48, 385-396. 
Lee, J. Y., Kwon, Y., Yang, S., Park, S., Kim, E. M., \& Na, E. Y. (2017). Differences in friendship networks and experiences of cyberbullying among Korean and Australian adolescents. The Journal of genetic psychology, 178(1), 44-57.

Maqrani, Mobaraka (2018), cyberbullying and its relationship with social anxiety, a field study on the students of second secondary grade who are addicted to social media sites in the city of Warqala, unpublished master thesis, the University of Qasidi Mirbah, Warqala, the faculty of human and social sciences, the department of psychology and education.

Nikolaou, D. (2017). Does cyberbullying impact youth suicidal behaviors?. Journal of health economics, 56, 3046.

Qotami, Naifa, Al-Sarayreh, Mona (2009), the bully child, first edition, Al-Masira House for publishing, distribution and printing, Amman, Jordan.

Reynolds, Cheryl, (2018) Digital Hiatus: Symbolic violence in an online social learning network for master's level students at a UK University, A thesis submitted to the University of Huddersfield in partial fulfillment of the requirements for the degree of Peluchette, J. V., Karl, K., Wood, C., \& Williams, J. (2015).

Sa'id, Yousry Sa'id Hassanein (2017), Cyberbullying through social communication networks and its relationship to the patterns of school violence, PhD, Naif Arab University for Security Sciences, the Faculty of Social Sciences, Department of Sociology, Criminology Department, Riyadh.

Sekol, I., \& Farrington, D. P. (2016). Personal characteristics of bullying victims in residential care for youth. Journal of aggression, conflict and peace research, 8(2), 99-113.

The Jordanian penal code, article (11), of the cyber crimes law.

Waasdorp, T. E., \& Bradshaw, C. P. (2015). The overlap between cyberbullying and traditional bullying. Journal of Adolescent Health, 56(5), 483-488.

Zohair, Mohammad, (2018), Bullying and its Relationship to the Social Phenomenon in Middle School Students, the Journal of the University of Babylon, the Faculty of Human Sciences, Volume (26), Issue (6), Babel, Iraq. 